\title{
The Impact of Noise on Hearing in Intensive Care Unit Nurses
}

\author{
Süheyla Abitağaoğlu', [MD] \\ ORCID: 0000-0003-4937-0080 \\ Alev Öztaş ${ }^{2},[\mathrm{MD}]$ \\ ORCID:0000-0002-8423-6824 \\ Fatma Şimşek Ceviz ${ }^{3}$, [MD] \\ ORCID: 0000-0002-4765-8518 \\ Ceren Köksal ',[MD] \\ ORCID: 0000-0003-4756-480X \\ Tuğba Aslan Dündar ${ }^{4}$, [MD] \\ ORCID: 0000-0001-8865-4567 \\ Güldem Turan ', [MD] \\ ORCID: 0000-0002-7281-1705 \\ Dilek Erdoğan Arı 1, [MD] \\ ORCID: 0000-0002-3734-5323

\begin{abstract}
${ }^{1}$ Anesthesiology and Reanimation Department, University of Health Sciences Fatih Sultan Mehmet Health Application and Research Center, Istanbul, Turkey 2Intensive Care, University of Health Sciences Fatih Sultan Mehmet Health Application and Research Center Istanbul, Turkey

${ }^{3}$ Occupational Medicine / Thoracic Surgery Department, University of Health Sciences Fatih Sultan Mehmet Health Application and Research Center, Istanbul, Turkey ${ }^{4}$ Otorhinolaryngology Department, University of Health Sciences Fatih Sultan Mehmet Health Application and Research Center, Istanbul, Turkey

Corresponding Author: Süheyla Abitağaoğlu

Anesthesiology and Reanimation Department,

University of Health Sciences Fatih Sultan Mehmet

Health Application and Research Center, E-5 Highway

İçerenköy Street 34752 Ataşehir İstanbul, Turkey.

Phone: +902165783000 - Extension:5502

E-mail address: suheylaatay81@gmail.com

DOI:10.32552/0.ActaMedica.386
\end{abstract}

Received:07 July 2019, Accepted: 19March 2020,

Published online: 31 March 2020

\section{nee ABSTRACT Cen}

Objective: The noise levels in the intensive care units exceed the levels suggested by the World Health Organization, because of the noises caused by devices and human noises. The aim of this study is to retrospectively examine the changes in audiometry results of nurses working in intensive care unit.

Materials and Methods: The audiometry results of nurses who worked for an uninterrupted period of 1 year in intensive care unit in the last 3 years were examined retrospectively based on the results recorded at the time of employment and in the last year of working. Age, gender, years of work, assessments of hearing level and high frequency hearing losses were recorded. The normal level of hearing was accepted as 0-25dB. Results: Totally 10 male (25.6\%), 29 female (74.4\%) were included in the study. The mean age was $26.97 \pm 4.69$ years and the mean time of employment was $1.82 \pm 0.91$ years. The mean values of pure tone levels, which were the measurements performed at $500-1000-2000 \mathrm{~Hz}$, were found to be subclinically increased in time. Two subjects (5.1\%) were confirmed to have high frequency hearing loss.

Conclusion: We believe that safety of the staff might be improved by reducing the level of noise in the intensive care units and identifying the people at risk with yearly audiometry follow-ups.

Keywords: Audiometry; hearing loss, noise-induced; intensive care unit; noise; nurses

\section{INTRODUCTION}

Noise is defined as 'unwanted sound' or 'sound that adversely affects the physiological and psychological state of a person or group of people' [1]. The noise level in intensive care units (ICUs) exceeds the levels recommended by the World Health Organization (WHO) owing to the mechanical noises and alarms of devices used in patient monitoring in ICUs, such as noise of monitors, mechanical ventilators and drug infusion pumps as well as noises caused by telephones and pagers and human noises caused by intensive care workers, consultants and patient relatives [2-4]. Noise is known to have many negative effects on patients in ICUs. In neonatal ICUs, noise can cause apnoea, bradycardia and increased blood pressure [4]. In adult intensive care patients, it causes sleep disorders and 
increased risk of delirium [5]. Similar to the effects of noise on patients, psychological and physiological adverse effects are observed in intensive care workers who are exposed to such noises for long periods of time. Prolonged exposure to high levels of noise can lead to hearing loss [2]. The aim of our study was to retrospectively evaluate the changes observed in the audiometric measurements performed during the annual routine health check-ups of nurses working in our ICU

\section{MATERIALS and METHODS}

After obtaining permission from the Hospital Scientific Studies Commission (2019/1231), a retrospective examination of 39 nurses was performed using audiometric measurements that were taken at their time of recruitment and at their last year of employment in the ICU. These nurses have been working regularly for 200 hours a month and for at least 1 year in our tertiary level ICU over the past 3 years.

Annual routine check-up including audiometric tests are performed by the workplace physician for the intensive care unit employees in our hospital. Audiometric data were obtained from the records of annual routine health check-up data at the time of employment and at 2018. Age, gender, duration of employment in the ICU, hearing level assessment and the presence of high frequency hearing loss, history of chronic otitis media during the employment period and whether tympanic membrane defects were identified during the otorhinolaryngology clinic examinations were recorded. With regards to the hearing level, $0-25 \mathrm{~dB}$ was considered normal, and higher sound levels were considered as hearing loss. In the hearing test, average hearing levels above $25 \mathrm{~dB}$ in the measurements performed at 500-1000-2000 Hz were considered as pure sound hearing loss and hearing values above $25 \mathrm{~dB}$ in the measurements performed at frequencies $\geq 4000 \mathrm{~Hz}$ were considered as high frequency hearing loss. Nurses working short-term or intermittently in the ICU, those with missing audiometric measurements and records, those with previous hearing loss and those with pathological findings related to the external auditory canal and eardrum in their otoscopic examination were excluded from the study.

\section{Statistical Analysis}

Statistical analysis was conducted using IBM SPSS Statistics 22 (SPSS IBM, Turkey) software. Normality of the data was evaluated using the Shapiro-Wilk test. Descriptive statistical methods (mean, standard deviation and frequency) were used when evaluating the study data, and the Wilcoxon sign test was used to compare quantitative data. A p value of $<$ 0.05 was considered to be statistically significant.

\section{RESULTS}

A total of 39 nurses aged 20-45 years were included in the study. Four nurses had chronic disease. The demographic data of the participants are shown in Table 1. The average noise level measured in 2018 by the workplace safety unit in the ICU was $60.1 \mathrm{~dB}(\mathrm{~A})$. It was found that none of the nurses had a history of chronic otitis media during the time of employment in the ICU, and no eardrum defect was identified during ear examinations.

When hearing levels were evaluated, it was observed that none of the nurses had hearing loss, but their pure hearing levels increased (Table 2). High frequency hearing loss was identified in two (5.1\%) nurses. When two nurses with high frequency hearing loss were examined, it was seen that neither of them had any chronic disease. 
Table 1. Demographic data

\begin{tabular}{|l|c|}
\hline Gender & $29(74.4 \%)$ \\
Female (\%) & $10(25.6 \%)$ \\
\hline Male (\%) & $26.9 \pm 4.6$ \\
\hline Age (years) Mean \pm SD & $1(2.5 \%)$ \\
\hline Chronic Disease & $1(2.5 \%)$ \\
Asthma (\%) & $1(2.5 \%)$ \\
Diabetes Mellitus (\%) & $1(2.5 \%)$ \\
Celiac Disease (\%) & $1.8 \pm 0.9(1)$ \\
\hline Arnold Chiari malformation (\%) & \\
\hline Employment in intensive care unit (years) & \\
Mean \pm SD (median) & \\
\hline
\end{tabular}

Table 2. Evaluation of pure sound averages

\begin{tabular}{|c|c|c|c|}
\hline & Basal & 2018 & $p$ \\
\hline Pure soundu average & Mean \pm SD (median & Mean \pm SD (median) & \\
\hline Right & $8 \pm 2.6(8)$ & $10 \pm 3(10)$ & $0,007^{*}$ \\
\hline Left & $7.7 \pm 2.8(7)$ & $9 \pm 2.9(10)$ & $0.009 *$ \\
\hline
\end{tabular}

\section{DISCUSSION}

Noise is known to cause many adverse psychological and physiological effects. Multiple studies have reported that noise causes problems such as increased stress, tachycardia, lack of motivation, burnout syndrome, lack of communication and increased margin of error in intensive care workers $[4,6,7]$. However, according to our knowledge, the impact of noise on hearing levels in intensive care workers had not been studied. We retrospectively evaluated the changes in hearing levels of nurses working in our ICU. We found that pure sound hearing levels increased in time and that two nurses had high frequency hearing loss.

In this study, it was observed that there was a subclinical change in the hearing levels of nurses working in the intensive care unit, during the period of working. In general population the main causes of sensorineural hearing loss are degenerative processes associated with aging, genetic mutations, chronic conditions and noise exposure [8]. The mean age of our study population was $26.9 \pm 4.6$ years. The fact that our patients are young indicates that the current changes are not age-dependent. Diabetes mellitus and uncontrolled glucose levels are risk factors for sensorineural hearing loss [9]. Celiac disease also can cause autoimmune sensorineural hearing loss [10]. In our study group one subject had celiac disease and one had diabetes mellitus but high frequency hearing loss was not seen in these two subjects. Noise level in intensive care is reported to be a risk factor for hearing loss in ICU patients [11]. When the available data and risk factors of whole study group were evaluated, the change in hearing is thought to be largely noise-dependent.

WHO has emphasized that noise levels in patient rooms should not exceed $35 \mathrm{~dB}(\mathrm{~A})$ during the day and $30 \mathrm{~dB}(\mathrm{~A})$ during the night [2]. However, a previous review reported noise levels in ICUs to be 50-70 $\mathrm{dB}(\mathrm{A})$ and that, in addition to the existing noise, sudden spikes in noise levels caused by alarms, pagers, telephones, opening and closing of doors and the rapid movement of objects used in ICUs can exceed $80 \mathrm{~dB}(\mathrm{~A})$ [12]. Existing data indicates the presence of high noise levels in ICUs. In our hospital, it was planned that noise measurements in ICUs would be performed annually by the workplace safety specialist beginning from 2018 , and the average noise level 
was found to be $60.1 \mathrm{~dB}(\mathrm{~A})$ in the measurements performed in 2018. In a previous study conducted by $A r$ et al. in our ICU, the lowest average noise level was found to be $48 \mathrm{~dB}(\mathrm{~A})$, whereas the highest average noise level was found to be $65 \mathrm{~dB}(\mathrm{~A})$ [3]. These levels are consistent with previous studies assessing noise levels in ICUs. Although the available data reflect the routine noise level in ICUs, they are insufficient for assessing the sudden spikes in noise levels. The most common cause of preventable hearing loss is noise-induced hearing loss [13]. Noiseinduced hearing loss may occur due to short-term sudden bursts of sound or continuous noise exposure [14]. Noise level and duration of exposure have been reported to be correlated with hearing loss [15]. The high levels of noise in ICUs represent an important problem. A study conducted on adult intensive care patients reported that along with trauma, infection, autoimmune diseases and ototoxic drugs, environmental noise may also lead to hearing loss [11]. It has been reported that premature babies in neonatal ICUs may develop mild hearing loss due to high noise levels [16]. However, the people who are exposed to noise in ICUs for the longest periods of time are intensive care workers, and in particular intensive care nurses. In the present study, an examination of the effect of noise on the hearing levels of intensive care nurses revealed that while there was no hearing loss in intensive care nurses with a mean employment duration of $1.8 \pm 0.9$ years, there was an increase in their pure hearing averages. Furthermore, two (5.1\%) nurses developed high frequency hearing loss. None of the nurses had a history of chronic otitis media. It has been reported that high frequency hearing loss is an indicator of longterm exposure to high noise levels and that noise-induced hearing loss is lower in exposures below 85 $\mathrm{dB}$ (8-h time weighted) [17]. Previous studies reported that more than $50 \%$ of the noise in ICUs may be caused by speech and human activities [18, 19]. One study reported that there was a decrease in worker-related noise after an awareness training was provided to intensive care workers [3]. In another study, a noise warning device was used in addition to awareness training, although it was also reported that behavioural changes alone are not sufficient to control the noise in ICUs, and that there is a need to consider structural features for noise control when making plans for new ICUs [6]. Based on an evaluation of our study data, it can be stated that the measures against noise, which constitutes an important risk for both patient and employee safety, should not be ignored in daily practise. At the same time, considering intensive care workers as a high-risk group for noise-induced hearing loss and performing annual audiometric controls may have positive effects in terms of increasing employee safety.

There are certain limitations to this study. The noise levels to which nurses were exposed to have not been measured over long periods of time given the retrospective nature of the study and the fact that there were no measurements for sudden spikes in noise levels. Additionally, it is not determined in our study whether nurses with high frequency hearing loss were exposed to high noise levels outside of work. It is therefore not possible to infer whether the hearing loss was caused solely by the noise exposure in the ICU. Another limitation of our study is that hearing was evaluated with audiometry only because the data were taken from routine health controls. Audiometry is an evaluation based on the patient's information and is a relatively subjective method [20]. Our study revealed a statistical significant difference of pure tone averages but the values were close to each other and inbetween normal ranges. If the hearing status could be evaluated by audiometry with an objective test like auditory brainstem response, more detailed results could be demonstrated. However, the increase in pure hearing levels in the study population despite their short working time suggests that noise may pose a risk to intensive care workers in the long-term, and that measures to counter this issue should be increased.

\section{CONCLUSION}

High noise levels in ICUs can adversely affect hearing levels, particularly among long-term workers. 
Although it is difficult to reduce the noise levels to those recommended by the WHO in an area with intensive equipment- and human-induced noise, such as intensive care, we believe that worker safety can still be enhanced by creating awareness about noise, establishing noise-reducing practices, taking necessary physical measures, and identifying individuals at risk through annual audiometry check-ups.

\section{CONFLICT OF INTEREST}

The authors declare that they have no conflict of interest.

\section{FUNDING}

This work was not supported financially by any third parties.

\section{ACKNOWLEDGEMENT}

We would like to thank Enago (www.enago.com) for English language editing.

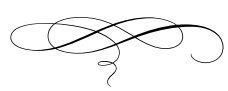


[1] Terzi B, Azizoğlu F, Polat Ş, et al. The effects of noise levels on nurses in intensive care units. Nurs Crit Care 2019; 24(5): 299-05.

[2] Berglund B, Lindvall T, Schwela DH. Guidelines for Community Health. World Health Organization: Geneva, 1999. https://apps.who.int/iris/handle/10665/66217

[3] $\operatorname{Ar} A Y$, Turan G, Alay $E E$, et al. Yoğun bakımda gürültü farkındalığı için neler yapabiliriz? Tur J Intens Care 2018; 16(1): 10-6.

[4] Chawla S, Barach P, Dwaihy M, et al. A targeted noise reduction observational study for reducing noise in a neonatal intensive unit. J Perinatol 2017; 37(9): 1060.

[5] Tainter CR, Levine AR, Quraishi SA, et al. Noise levels in Surgical ICUs are consistently above recommended standards. Crit Care Med 2016; 44(1): 147-52.

[6] Konkani A, Oakley B. Noise in hospital intensive care units-a critical review of a critical topic. J Crit Care 2012; 27(5): 522.e1-9.

[7] Darbyshire JL. Excessive noise in intensive care units. BMJ 2016; 353: i1956.

[8] Cunningham LL, Tucci DL. Hearing Loss in Adults. N Engl J Med 2017; 377(25): 2465-73.

[9] Kim MB, Zhang Y, Chang Y, et al. Diabetes mellitus and the incidence of hearing loss: a cohort study. Int J Epidemiol 2017; 46(2): 717-26.

[10] Suchan M, Kaliarik L, Krempaska S, et al. Immunemediated cochleovestibular disease. BratisI Lek Listy 2016; 117(2): 87-90.

[11] Halpern NA, Pastores SM, Price JB, et al. Hearing loss in critical care: an unappreciated phenomenon. Crit Care Med 1999; 27(1): 211-9.
[12] Horsten S, Reinke L, Absalom AR, et al. Systematic review of the effects of intensive-care-unit noise on sleep of healthy subjects and the critically ill. BJA 2018; 120(3): 443-52.

[13] Stucken, EZ, Hong RS. Noise-induced hearing loss: an occupational medicine perspective. Curr Opin Otolaryngol Head Neck Surg 2014; 22(5): 388-93.

[14] [Basner M, Babisch W, Davis A, et al. Auditory and nonauditory effects of noise on health. Lancet 2014; 383: 1325-32.

[15] [Hong $\mathrm{O}$, Kerr M, Poling G, et al. Understanding and preventing noise induced hearing loss. Dis Mon 2013; 59: 110-18.

[16] Li WG, Jiang HB, Gan T, et al. Effect of noise on the auditory system and the intelligence development of premature infants treated in the neonatal intensive care unit. Chinese J Contemp Paediatr 2009; 11(12): 976-9.

[17] Kirchner DB, Evenson E, Dobie RA, et al. Occupational noise-induced hearing loss: ACOEM Task Force on Occupational Hearing Loss. J Occup Environ Med 2012; 54(1): 106-8.

[18] Akansel N, Kaymakçi S. Effects of intensive care unit noise on patients: A study on coronary artery bypass graft surgery patients. J Clin Nurs 2008; 17: 1581-90.

[19] Park M, Kohlrausch A, de Bruijn W, et al. Analysis of the soundscape in an intensive care unit based on the annotation of an audio recording. J Acoust Soc Am 2014; 135(4): 1875-86.

[20] Hoth S, Baljić I. Current audiological diagnostics. GMS Curr Top Otorhinolaryngol Head Neck Surg 2017;16. 